\title{
Nanoscale Forces between Basal Mica Surfaces in Dicarboxylic Acid Solutions: Implications for Clay Aggregation in the Presence of Soluble Organic Acids
}

\author{
Joanna Dziadkowiec* and Anja Rфyne
}

Cite This: Langmuir 2020, 36, 14978-14990

Read Online

ACCESS | Lلll Metrics \& More | 国 Article Recommendations ｜ sl Supporting Information

ABSTRACT: The stability of organomineral aggregates in soils has a key influence on nutrient cycling, erosion, and soil productivity. Both clay minerals with distinct basal and edge surfaces and organic molecules with reactive functional groups offer rich bonding environments. While clay edges often promote strong inner-sphere bonding of - $\mathrm{COOH}$-laden organics, we explore typically weaker, outer-sphere bonding of such molecules onto basal planes and its significance in organomineral interactions. In this surface force apparatus study, we probed face-specific interactions of negatively charged mica basal surfaces in solutions containing carboxyl-bearing, low-molecular-weight dicarboxylic acids (DAs). Our experiments provide distance-resolved, nanometer-range measurements of forces acting between two (001) mica surfaces and simultaneously probe DA adsorption. We show that background inorganic ions display crucial

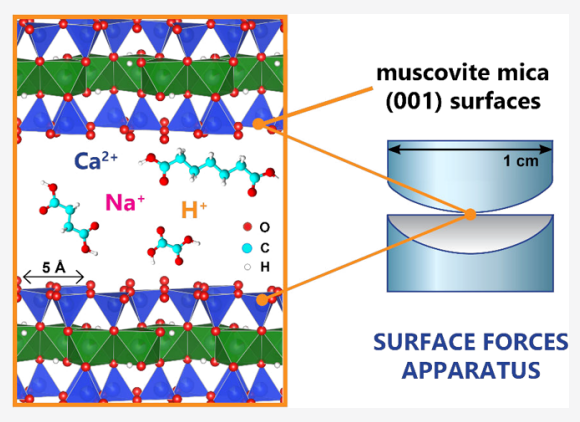
importance in nanoscale forces acting between basal mica surfaces and in DA adsorption: $\mathrm{Na}^{+}$contributes to strong repulsion and little binding of dicarboxylic anions, while small amounts of $\mathrm{Ca}^{2+}$ are sufficient to screen the basal surface charge of mica, facilitate strong adhesion, and enhance dicarboxylic anion adsorption by acting as cationic bridges. Despite reversible and weak adsorption of DAs, we resolve their multilayer binding via assembly of hydrophobic chains in the presence of $\mathrm{Ca}^{2+}$, pointing the importance of abundant, less reactive basal clay surfaces in organomineral interactions.

\section{INTRODUCTION}

Low-molecular-weight organic acids are being constantly supplied to soils and sediments by plant roots and microorganisms during oxidative decomposition of soil organic matter. As decomposition progresses, nonpolar organic molecules become reduced in size, depolymerized, and enriched in ionizable functional groups containing oxygen atoms, which renders the formed organic species more chemically reactive and water-soluble. ${ }^{1}$ Carboxylic functional groups, with relatively high negative hydration energies, ${ }^{1,2}$ are essential for the high solubility of small organic molecules in aqueous solutions and are almost always present in the dissolved fractions of organic matter, ${ }^{1,3}$ both of natural and anthropogenic origin. ${ }^{4}$

Despite their relatively high solubility, low-molecular-weight organic molecules $\left(\ll \mathrm{kDa}^{5,6}\right)$ can persist in soils and sediments for years. ${ }^{7-9}$ Their long-time retention is often attributed to the interactions with oxides, ${ }^{10,11}$ hydroxides, ${ }^{12-14}$ and clay minerals, ${ }^{15,16}$ which are common secondary mineral phases formed during pedogenesis. Layered phyllosilicate clays are especially important because of their high abundance in the soil matrix, large specific surface areas, and thus extensive adsorptive capacities. ${ }^{7,17-19}$ Although both clay mineral surfaces and soluble organic acid molecules are generally net negatively charged in a wide range of $\mathrm{pH}$ conditions, substantial adsorption of acidic organic species can occur at specific surface sites of clays and via nonelectrostatic interactions. ${ }^{6}$ Adsorption of organic molecules onto clay surfaces often involves carboxylic $-\mathrm{COOH}$ functionalities. ${ }^{1,4,6,20-27}$

Molecular mechanisms of interactions between clay minerals and carboxyl-bearing small organic molecules, such as carboxylic acid and dicarboxylic acid (DA), in aqueous solutions are most often examined by Fourier-transform infrared spectroscopy ${ }^{15,22-24,26,28-34}$ and force spectroscopy ${ }^{27}$ and via computer simulations..$^{21,22,25,35-37}$ Clay crystals exhibit two very distinct adsorption sites: crystal edges displaying $\mathrm{pH}$ dependent surface charge because of abundant surface hydroxyl groups ( $\equiv \mathrm{Si}-\mathrm{OH}, \equiv \mathrm{Al}-\mathrm{OH})$ and basal (001) planes with permanent negative surface charge caused by isomorphic ionic substitutions in tetrahedral (e.g., $\mathrm{Al}^{3+} \rightarrow \mathrm{Si}^{4+}$ ) or octahedral layers (e.g., $\left.\mathrm{Mg}^{2+} \rightarrow \mathrm{Al}^{3+}\right) .{ }^{38}$ Some organic compounds can be additionally adsorbed inside the interlayer spaces of certain clay types (e.g., smectites). ${ }^{38}$ Edge hydroxyl groups comprise a highly versatile bonding environment in

Received: August 4, 2020

Revised: November 14, 2020

Published: December 1, 2020 


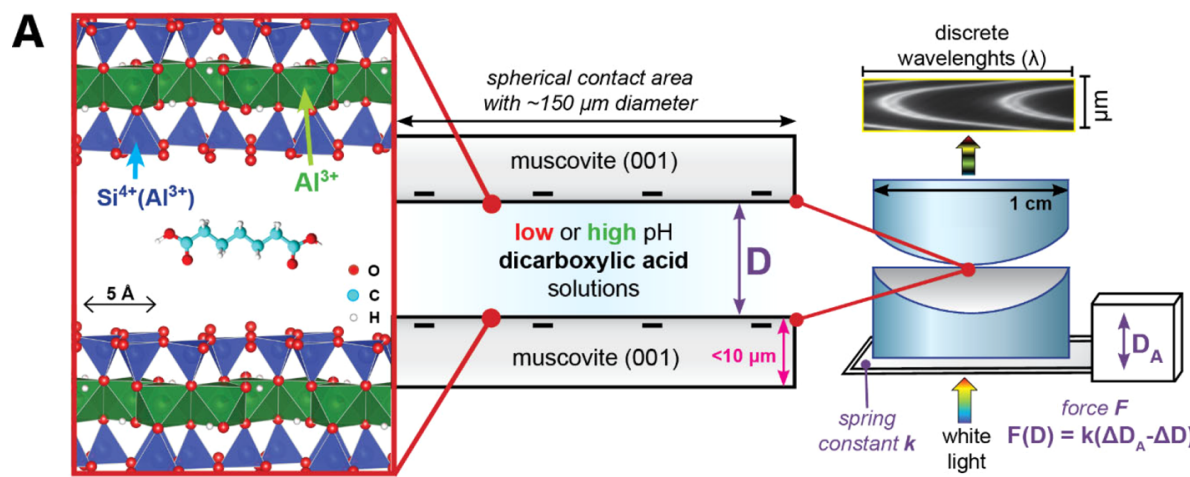

B

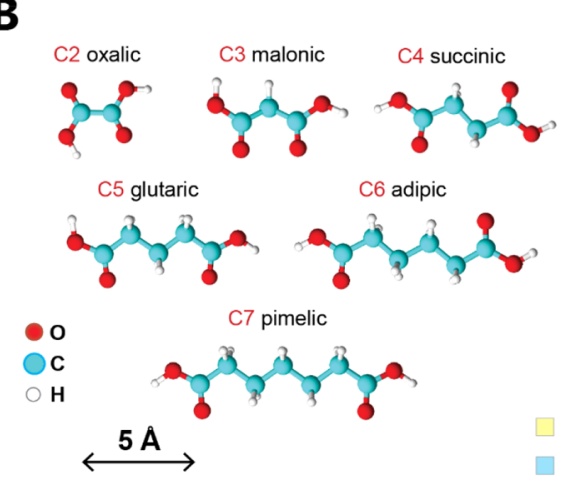

dicarboxylic acids concentration $50 \mathrm{mM}$

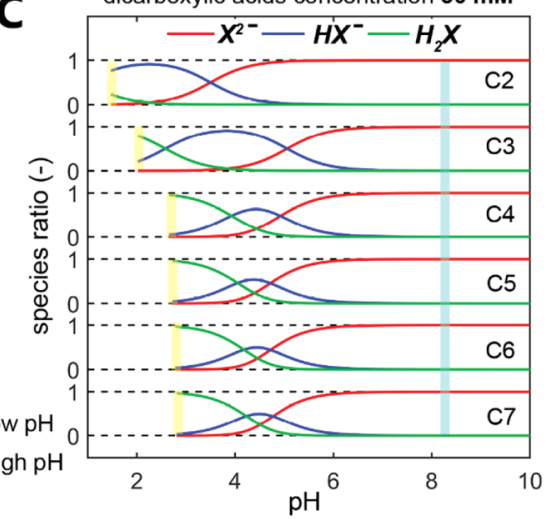

Figure 1. (A) Schematic representation of the SFA setup: normal forces (F) are measured between two atomically smooth (001) muscovite mica surfaces as a function of distance (D) between them in low- or high-pH DA solutions; $D_{\mathrm{A}}$ is applied displacement. The mica structure in the left panel was drawn using VESTA software; ${ }^{61}$ (B) C2-C7 DA molecules with structures drawn and optimized in ACD/ChemSketch software; (C) speciation of $50 \mathrm{mM}$ DAs dissolved in water as a function of $\mathrm{pH}$, calculated with PhreeqC based on the dissociation constants shown in Table S5. $\mathrm{X}^{2-}$ is an organic anion because of the full dissociation of diprotic acids. The yellow shadings mark low-pH value experiments (pure dissociated 50 $\mathrm{mM}$ DAs) and blue shadings mark the $\mathrm{pH}$ value used in the high-pH (8.3; adjusted by adding $\mathrm{NaOH})$ experiments.

which carboxyl groups can bind in three major ways: (1) as inner-sphere complexes via strong covalent bonds between carboxylic $\mathrm{C}-\mathrm{O}$ and surface metal atoms $(-\mathrm{OH}$ exchanged with $-\mathrm{COOH}$ ) and as outer-sphere complexes by (2) electrostatic forces between surface (de)protonated hydroxyls and carboxylic groups or (3) hydrogen bonding between oxygen and hydrogen atoms in various configurations. While strong covalent bonds are more likely to form at low $\mathrm{pH}^{23,24}$ all these adsorption modes are believed to coexist under most aqueous medium conditions. ${ }^{21,25}$ Adsorption on basal (001) planes is usually weaker and involves multiple hydrogen bonds between often partially hydrated carboxylic groups and surface $\mathrm{O}$ atoms. $^{22,35,36,39}$ In all cases, binding of organic molecules onto clay surfaces is highly influenced by multivalent ions: inorganic cations can complex $-\mathrm{COOH}$ groups and significantly enhance adsorption of organic species onto negatively charged surfaces via cation bridging (with $\mathrm{Ca}^{2+}$ acting more efficiently under alkaline conditions with deprotonated $\left.-\mathrm{COO}^{-}\right){ }^{21,23,33,40-43}$

Adsorption of organic species onto clay minerals considerably alters clay's surface properties, which in turn largely affects the aggregation of clay crystals, changes the structure of the soil matrix, and governs the transport of dissolved matter (including nutrients and pollutants) through clay-rich horizons. $^{1,4,6,7,26,44}$ Batch colloidal stability experiments indicate that adsorbed acidic organic molecules usually render clay surfaces more negatively charged and prevent clay aggregation by enhancing or inducing electrostatic repulsion between the individual platelets, often over a wide range of $\mathrm{pH}$ conditions. ${ }^{6,45-48}$ Other environmental factors, such as multivalent cations (especially $\mathrm{Ca}^{2+}$ ), may, however, reverse this trend. ${ }^{6,49}$ Efficiency in clay aggregate formation depends also on the structure of organic molecules, that is, mutual positions of reactive functional groups (e.g., $-\mathrm{COOH}){ }^{20}$

As oxide-like, amphoteric edge clay surfaces generally favor stronger binding of soluble organics than tetrahedral clay faces with permanent negative charge, ${ }^{23,26,29,31,34,46,47,50-52}$ edge sites are often reported to affect the formation of organoclay aggregates to a larger extent than basal surfaces ${ }^{20,46,47,51,52}$ (see also Supporting Information, Table S1). However, recent facespecific force spectroscopy experiments of Newcomb et al. ${ }^{27}$ reported highly $\mathrm{pH}$-dependent binding of $-\mathrm{COOH}$ functionality to basal (001) mica surfaces: the binding force measured at $\mathrm{pH} 4$ was an order of magnitude higher than that at $\mathrm{pH} 8$. Such face-specific information is not available in batch colloidal stability experiments, which provide averaged information about basal planes and edges. ${ }^{27}$ As broken clay edges comprise only $<10 \%$ of the accessible surface area, the majority being basal (001) planes, ${ }^{33}$ more insight into the individual behavior of basal clay planes is needed to unravel their detailed aggregation behavior in the presence of soluble organics.

In this work, we present direct-surface-force apparatus (SFA) measurements of normal forces acting between basal (001) planes of muscovite mica clay surfaces in aqueous solutions of small DAs (Figure 1A). Unlike atomic force microscopy, the SFA provides information about the 
separation between two probed surfaces with a sub-nanometer accuracy $^{53}$ in a symmetric surface configuration, which allows the detection of any substantial adsorbed layers. ${ }^{53}$ The nanoscale forces measured in DA solutions at acidic and basic $\mathrm{pH}$ and in the presence of mono and divalent inorganic cations provide a systematic insight into face-face aggregation of negatively charged clay minerals in contact with small, carboxyl-bearing organic molecules.

\section{MATERIALS AND METHODS}

Mica Surfaces. We measured surface forces between two atomically smooth mica surfaces, cleaved along (001) planes. ${ }^{54}$ Freshly cleaved pieces of optical grade muscovite mica (S\&J Trading Inc., USA) with a uniform thickness $(1-10 \mu \mathrm{m})$ were back-coated with a 55-nm thick Ag layer using a Balzers BAE 250 thermal evaporator. The pieces of cleaved mica were cut with sharp and clean scissors. All samples were handled in a laminar flow cabinet. EPON1004 hot-melt resin (supplied by SurForceLLC, USA) was used to glue the Ag-coated mica to the cylindrical SFA disks (here with a radius of curvature $R=0.02 \mathrm{~m}$ ), which were crossed at an angle of $90^{\circ}$ to yield a spherical nominal contact area with a radius of $\sim 50$ $\mu \mathrm{m}$.

Force Measurements. Nanometer-range forces were measured as a function of the distance $(D)$ between two opposing surfaces using the SFA ( SFA2000; SurForce LLC, USA). ${ }^{53}$ The SFA technique uses optical multiple beam interferometry $(\mathrm{MBI})^{55,56}$ to measure the distance $(D)$ between the surfaces. The bottom surface is mounted on a force measuring spring with a spring constant $k$ (here $k=2000 \mathrm{~N} /$ $\mathrm{m})$. The spring is moved vertically by an actuator at a constant velocity, giving a known displacement $\left(D_{\mathrm{A}}\right)$. If any force $F(D)$ acts between the surfaces, it will deflect the force measuring spring and $\Delta D \neq \Delta D_{\mathrm{A}} . F(D)$ can be then calculated as $F(D)=k\left(\Delta D_{\mathrm{A}}-\Delta D\right)$. To measure $D$ using MBI, white light is transmitted through the two opposing semireflective samples that together with the liquid confined between the surfaces comprise an interferometer (Ag-mica-fluid-mica$\mathrm{Ag}$ interferometer). The direction of the transmitted light is normal to the interfaces of the interferometer. The light transmitted through the interferometer is detected using a spectrometer (Princeton Instruments IsoPlane SCT320 with a PIXIS2048B camera; resolution of $0.624 \mu \mathrm{m} / \mathrm{pixel}$ ) as fringes of equal chromatic order (FECO), the wavelength positions of which depend on thicknesses $(d)$ and refractive indices $(n)$ of all the layers comprising the interferometer. Usually, only the thickness of the water film confined between two surfaces $(=D)$ is unknown and can be recalculated from the FECO pattern. To recalculate $D$ from FECO positions in mica-mica experiments, we used Reflcalc open-source software modeling ${ }^{56,57}$ or the analytical interferometer solution. ${ }^{58}$ All calculations were performed in MATLAB software. The details of Reflcalc and MATLAB analysis are provided in the study by Dziadkowiec et al. ${ }^{59}$ and Supporting Information therein.

Solutions. Forces were measured in $50 \mathrm{mM}$ DA solutions. We used DAs with two to seven carbon atoms (oxalic, malonic, succinic, glutaric, adipic, and pimelic acids; Merck, 99\%; Figure 1B). The solubility of DAs in water decreases with an increasing number of carbon atoms in aliphatic chains, but the concentrations we used were much lower than the solubility of the least soluble acid, $\mathrm{C} 7$, which has a solubility of approx. $\sim 0.3 \mathrm{M}$.

We performed two types of experiments with DAs. In the first type of experiments, forces were measured both in low-pH DA solutions (without adjusting the $\mathrm{pH}$ ) and in high- $\mathrm{pH}$ 8.2-8.4 solutions (adjusted only with $\mathrm{NaOH}$; Table S2). For each DA solution, we used fresh mica surfaces and measured forces in the same contact region: first in distilled $\mathrm{H}_{2} \mathrm{O}$, then in a low-pH DA solution, and last in a high$\mathrm{pH}$ DA solution. In the second type of experiment, we measured forces in high-pH DA solutions in which $\mathrm{pH}$ was partially adjusted with varying amounts of $\mathrm{Ca}(\mathrm{OH})_{2}$ (1 to $20 \mathrm{mM}$ ) and further adjusted to 8.2-8.4 with $\mathrm{NaOH}$. Here, we measured forces in: (a) $50 \mathrm{mM}$ adipic acid (C6) solutions as a function of $\mathrm{Ca}^{2+}$ concentration $(1,5$, 20, and $40 \mathrm{mM}$; Table S3); and (b) in DAS from C3 to C7 with 5
$\mathrm{mM}$ of $\mathrm{Ca}^{2+}$ (Table S4). In (b), we used one contact between mica surfaces, and after each DA solution, we measured forces in Milli-Q water (every time we injected water, the $150 \mathrm{~mL}$-volume SFA chamber was rinsed with additional $300 \mathrm{~mL}$ of Milli-Q water).

We additionally performed three types of control experiments without DAs to investigate the effect of: (a) low $\mathrm{pH}$ ( $\mathrm{pH} 2.70,2.00$, 1.47 , and 1.40 adjusted with $\mathrm{HCl}$; Table S2); (b) $\mathrm{Ca}^{2+}$ concentration $\left(1,5\right.$, and $20 \mathrm{mM}$ adjusted with $\mathrm{CaCl}_{2}$; Table S3); and c) ionic strength $\mathrm{IS}=0.15 \mathrm{M}$ (adjusted with $\mathrm{NaCl}$ ) at high $\mathrm{pH}=8.3$ (adjusted with $\mathrm{NaOH}$; Table S2) on forces acting between mica surfaces. In (b), $\mathrm{Ca}^{2+}$ and $\mathrm{Na}^{+}$were adjusted to the same levels as in corresponding experiments with $\mathrm{DAs}$ with $\mathrm{CaCl}_{2}$ and $\mathrm{NaCl}$ salts. In (a), no additional salts were added.

To avoid any possible contamination, every time we replaced a solution in the SFA chamber, we separated the surfaces and rinsed the chamber first with $\sim 150 \mathrm{~mL}$ of distilled water, then with $\sim 150 \mathrm{~mL}$ of the new solution, before the last $\sim 150 \mathrm{~mL}$ solution injection in which we measured the forces. All solutions were prepared just before the experiments using Milli-Q $(18.2 \mathrm{M} \Omega / \mathrm{cm})$ water and filtered using 0.2 $\mu \mathrm{m}$ polyether-sulfone membrane syringe filters. Figure $1 \mathrm{C}$ shows the speciation of DAs as a function of $\mathrm{pH}$ calculated in PhreeqC software using the dissociation constants $\mathrm{pK}_{\mathrm{a} 1}$ and $\mathrm{pK}_{\mathrm{a} 2}$ summarized in Table S5.

Reference Measurements in Water. In each experiment, we only used pairs of mica surfaces that showed an attractive jump-in on approach and a considerable adhesion measured on retraction in Milli- $\mathrm{Q}$ water. The average adhesion (pull-off force) measured in Milli-Q water for 21 pairs of mica surfaces used in this work was 63.3 $\pm 26.2 \mathrm{mN} / \mathrm{m}$, with minimum and minimum values of 21.1 and 118.1 $\mathrm{mN} / \mathrm{m}$ (see Tables S2-S4). This variability is related to the natural origin of mica surfaces and possible effects of: surface defects, inhomogeneity in mica chemical composition, trace contamination, and misalignment of surface lattices of the two opposing mica surfaces. ${ }^{60}$ As such, when comparing adhesion values between different pairs of mica surfaces, we always report the reference adhesion measured in water at the start of each experiment.

The optical 'zero' separation between mica surfaces was always determined for each pair of mica surfaces as the hard wall contact position (HP) measured after the attractive jump-in on approach measured in Milli- $Q$ water at the start of each experiment. Hard wall positions measured for DA solutions and control solutions are reported as shifts with respect to each Milli- $Q$ water reference at a given applied load value. This facilitates comparison of hard wall positions between different pairs of mica surfaces.

\section{RESULTS AND DISCUSSION}

A schematic representation of the experimental SFA setup used in this work is sketched in Figure 1A: Forces were measured between two atomically smooth (001) mica basal surfaces in C2-C7 DA solutions (Figure 1B) at low (1.4-2.7, depending on $50 \mathrm{mM}$ DA dissociation) and high $(8.2-8.4) \mathrm{pH}$. Although low $\mathrm{pH}$ values of pure DA solutions do not correspond to typical soil $\mathrm{pH}$, they let us assess DA binding in the absence of foreign ions. The slightly basic $\mathrm{pH}$ of 8.3 was chosen a condition where all DAs are fully dissociated. The speciation of $\mathrm{DAs}$ at a given $\mathrm{pH}$ is plotted as a function of $\mathrm{pH}$ in Figure 1C. At $\mathrm{pH}<3, \mathrm{C} 4-\mathrm{C} 7 \mathrm{DA}$ molecules remain dominantly in an undissociated form $\mathrm{H}_{2} \mathrm{X}$ (where $\mathrm{X}^{2-}$ is a fully dissociated DA anion), with a small proportion of $\mathrm{HX}^{-}$. For $\mathrm{C} 2$ and $\mathrm{C} 3$, there is a substantial amount of $\mathrm{HX}^{-}$species. At $\mathrm{pH}>8$, all DAs are fully dissociated to divalent $\mathrm{X}^{2-}$ species.

Figure $2 \mathrm{~A}$ shows an overview of the measured forces in lowand high-pH pimelic acid solutions (C7): in general, for all DAs, we measured adhesive forces at low $\mathrm{pH}$ and repulsive forces in high-pH solutions (apart from oxalic acid C2 solution, with repulsive forces measured under both $\mathrm{pH}$ conditions). We also observed a reproducible shift of HPs in 
A

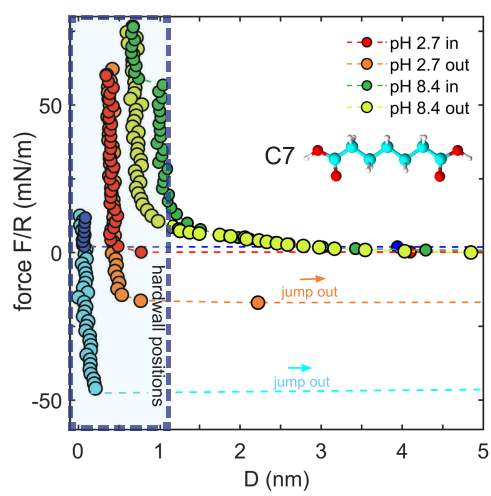

Figure 2. (A) Shift in HPs in representative forces (F) measured as a function of distance (D) between two mica surfaces in MilliQ water and in $50 \mathrm{mM}$ pimelic acid solutions ( $\mathrm{pH} 2.7$ and 8.4). All measurements were performed with the same set of mica surfaces in the same contact region. $F$ was normalized with the radius of curvature (R); (B) HPs in force measurements between two mica surfaces in DA solutions at low and high $\mathrm{pH}$ as a function of number of carbon atoms $\mathrm{C}$ in DA molecules, determined at an applied load of $\sim 35 \mathrm{mN} / \mathrm{m}$ (and $10 \mathrm{mN} / \mathrm{m}$ for each water reference). Top and bottom panels show measurements for two duplicate experiments with the same conditions separately (set 1 , set 2; see Table S2 for solution conditions). For each DA solution, a new set of mica surfaces was used, and forces were measured first in $\mathrm{H}_{2} \mathrm{O}$, then in low-pH (1.4 for $\mathrm{C} 2,2.0$ for $\mathrm{C} 3,2.7$ for $\mathrm{C} 4-\mathrm{C} 7)$ solution, and last in high-pH (8.3) solution. The HP for each experiment was shifted to set the HP in water at $0 \mathrm{~nm}$ (optical "zero" separation).

DA solutions: all HPs were shifted to higher separations with respect to those measured in MilliQ water (which are defined as an optical zero separation in this work), with the largest shifts observed for high-pH solutions.

Interfacial Structure. The binding modes of DAs and interfacial structure of mica surfaces in DA solutions can be reconstructed by analyzing the force distance curves at small surface separations (D $<2 \mathrm{~nm}$ ). Because the SFA measurements provide information about the absolute distance between surfaces, ${ }^{53}$ the shift of the HP to larger separations is indicative of strong steric repulsive force components, which prevent the mica surfaces from coming into direct contact. This short-range steric repulsion may indicate the accumulation of layers of hydrated inorganic counterions ${ }^{62}$ or DA molecules in the vicinity of charged mica surfaces. To detect whether the observed HP shifts were related to adsorption of DAs in the interlayer region, we measured forces in control inorganic solutions with the corresponding $\mathrm{pH}$ and ionic strength and with the same concentration of $\mathrm{Na}^{+}$(for the measurements at high $\mathrm{pH}$ adjusted with $\mathrm{NaOH}$ ). A summary of HPs measured in all low and high-pH DA solutions and in control experiments is plotted in Figure 2B.

At $\mathrm{pH} 1.4$ (the lowest-pH solution used in these experiments, corresponding to $50 \mathrm{mM}$ oxalic acid $\mathrm{C} 2$ solution), the mica surface is positively charged because of an excess of surface-adsorbed hydrogen species. ${ }^{63,64}$ At this $\mathrm{pH}$, we measured substantial shifts of HPs to larger separations, both for the $\mathrm{pH} 1.4$ control experiments and $\mathrm{C} 2$ solutions $\left(\sim 2 \mathrm{~nm}\right.$ HP shifts with respect to $\mathrm{H}_{2} \mathrm{O}$; Figure $\left.2 \mathrm{~B}\right)$. Because $\mathrm{H}_{3} \mathrm{O}^{+}$species do not form a pronounced hydration structure on mica surfaces, ${ }^{65,66}$ the large shift in HPs measured

in the inorganic $\mathrm{pH} 1.4$ control solution $(\mathrm{HCl})$ can be attributed to repulsive forces linked with coadsorption of hydrated $\mathrm{Cl}^{-}$anions. ${ }^{63}$ In low-pH oxalic acid (C2) solution, the HP shifted to even larger separations than in the control force runs, and forces were strongly repulsive, indicating a significant adsorption of $\mathrm{C} 2 \mathrm{DA}$ onto the mica surfaces (Figure 2B). The adsorption of oxalate $\mathrm{HC}_{2} \mathrm{O}_{4}^{-}$anions (dominant at this $\mathrm{pH}$ ) most likely occurs via electrostatic interactions with the positively charged mica surfaces. The charged C2 species rather formed a disordered anion layer, nonspecifically adsorbed to the mica. This is because a strong specific surface adsorption is often revealed by small jump-in events in the force measurements (corresponding to squeezing out of surface-bound species ${ }^{63}$ ), which we did not observe.

At $\mathrm{pH} 2.0$ (measured for $50 \mathrm{mM}$ malonic C3 acid), mica surfaces are still slightly positively charged because of an excess of protons. ${ }^{63,64}$ However, in contrast to the $\mathrm{pH} 1.4$ solutions, the HPs that we measured in the inorganic $\mathrm{pH} 2.0$ control experiments were not shifted with respect to the water reference. Similarly, no major, reproducible shift in HPs was observed for C3 DA solutions (a significant HP shift was measured only in set 1 experiments). This suggests that a small magnitude of the positive surface charge of mica led to no strong or substantial adsorption of $\mathrm{Cl}^{-}$or $\mathrm{H}_{3} \mathrm{C}_{3} \mathrm{O}_{4}^{-}$anions on mica surfaces. However, a small amount of charged $\mathrm{C} 3$ species (undissociated C3 molecules start to dominate, see Figure 1C) could have been electrostatically adsorbed onto positively charged mica surfaces in a similar way to $\mathrm{C} 2$ oxalate anions.

At $\mathrm{pH} \sim 3$, which was measured for $50 \mathrm{mM} \mathrm{C} 4-\mathrm{C} 7$ solutions, the mica surface is close to its point of zero charge $(\mathrm{pZc}),{ }^{63,64,67}$ as there is still a sufficient amount of protons to neutralize its negative surface charge. At this $\mathrm{pH}$, the inorganic control experiments showed no shift of HPs to larger separations with respect to the $\mathrm{H}_{2} \mathrm{O}$ reference (Figure 2B). This is because, close to $\mathrm{pZc}$, we expect no substantial steric hydration repulsion because of few coadsorbed anions. We also did not observe any pronounced shift of HPs for low-pH 50 $\mathrm{mM} \mathrm{C4-C7} \mathrm{DA} \mathrm{solutions,} \mathrm{which} \mathrm{indicates} \mathrm{that} \mathrm{the} \mathrm{C4-C7} \mathrm{do}$ not adsorb strongly to mica surfaces (a prominent shift was measured for $\mathrm{C} 5$, however, only in set 2 experiments). Our C4-C7 DA solutions at this $\mathrm{pH}$ are almost fully composed of undissociated species (Figure 1C). These neutral molecules are most likely bound to mica surfaces only by weak hydrogen bonds. ${ }^{22}$ This means that they could have been easily displaced from the interlayer region upon compression, explaining no significant shifts in HPs.

All of the DAs used in this study undergo almost full dissociation at $\mathrm{pH}>6$, and thus, the dominant DA species in our high-pH solutions $(8.2-8.4)$ are divalent organic anions (Figure 1C). These solutions also have much higher ionic strength (IS $=0.15 \mathrm{M}$ ) than those used in the low-pH experiments because of a high amount of added $\mathrm{Na}^{+}(\mathrm{pH}$ was adjusted with $\mathrm{NaOH}$ ). The $\mathrm{HP}$ measured in the inorganic $\mathrm{NaCl}$ control solution $(\mathrm{pH} 8.3$, IS $=0.15 \mathrm{M}$; Figure 2B) was substantially shifted to larger separations with respect to the $\mathrm{HP}$ in water (by $<1 \mathrm{~nm}$ ). As mica surfaces are negatively charged at this $\mathrm{pH}$ (monovalent $\mathrm{Na}^{+}$ions do not efficiently screen the negative surface charge of mica because they keep their hydration shells ${ }^{66}$ ), a high amount of hydrated $\mathrm{Na}^{+}$ cations are expected to adsorb onto surfaces as outer-sphere species, ${ }^{68}$ resulting in strong repulsive short-range hydration forces. ${ }^{69}$ These forces prevent the mica surfaces from coming into direct contact (as the energy required to dehydrate and 
squeeze-out surface adsorbed $\mathrm{Na}^{+}$is relatively high ${ }^{68,69}$ ) and caused the observed shift in the HP to larger separations.

The shifts in hard wall positions measured for high-pH DA solutions are in most cases slightly larger than the HP shifts in the inorganic high-pH control (Figure 2B), suggesting the enhanced accumulation of DA anions close to the mica surfaces in comparison with $\mathrm{Cl}^{-}$in the control. As both mica and dicarboxylic anions are negatively charged in this case, the DA coions should be depleted in the interlayer region. ${ }^{70}$ However, it is possible that a small proportion of DA molecules remain in the interlayer by forming complexes with $\mathrm{Na}^{+}$. The association of monovalent ions with deprotonated $-\mathrm{COO}^{-}$groups of DAs is rather weak (with $p K_{a}$ for formation of bulk $\mathrm{NaX}^{-}$complexes generally $<1$, as reported by Daniele et al.; ${ }^{71}$ see Table S6), and these species still remain negatively charged; however, binding to surfaceadsorbed $\mathrm{Na}^{+}$(possibly indirectly via water bridges ${ }^{72}$ ) would most likely explain the possible enhanced accumulation of DAs in the electrical double layer (EDL) with respect to $\mathrm{Cl}^{-}$. We suggest only very minor adsorption of $\mathrm{DA}$ at high $\mathrm{pH}$ in the presence of $\mathrm{Na}^{+}$: If DAs bound very strongly to the mica, we should have been able to observe an effect of the increasing hydrophobicity for larger DAs reflected by a reproducible correlation between HP shifts and the number of $\mathrm{C}$ atoms in aliphatic chains of DA. Nevertheless, we did not observe such correlation (Figure 2B).

Adhesion and Forces Measured at Low pH. Adhesion forces measured with SFA provide direct information about face-specific aggregation behavior of mica surfaces and are closely related to the mica interfacial structure. ${ }^{66,69}$ In general, mica surfaces in water attract each other because of van der Waals (VdW) interactions, as indicated by the high measured pull-off forces (force required to separate the surfaces from adhesive contact) plotted in Figure $3 \mathrm{~A}$. Ions and molecules present at interfaces in substantial concentrations can, however, decrease the surface adhesion, as moderate compressive pressures $(<50 \mathrm{mN} / \mathrm{m})$ are often insufficient to displace strongly adsorbed species from the interfacial region. Because mica used in this work is a natural mineral, the adhesion values measured between individual pairs of mica surfaces may vary depending on their surface characteristics. To facilitate the comparison of adhesion measured for different pairs of mica surfaces, we report the reference adhesion measured in water for each mica pair used in this work (see the Materials and Methods section and Supporting Information, Tables S2-S4).

Figure $3 \mathrm{~A}$ shows the comparison of the adhesion (pull-off forces) measured on retraction in low-pH DA solutions: adhesion was the highest for $\mathrm{C} 4-\mathrm{C} 7 \mathrm{DA}(\mathrm{pH} \sim 2.7)$, lower for $\mathrm{C} 3(\mathrm{pH} 2.0)$, and not detected for $\mathrm{C} 2(\mathrm{pH} 1.4)$. The same trend was observed for the corresponding $\mathrm{pH}$ inorganic control experiments (yellow areas in Figure 3A; pull-off force in $\mathrm{pH} 1.4$ control was $<1 \mathrm{mN} / \mathrm{m}$ ), pointing to a strong influence of surface adsorbed protons on mica adhesion. These strongly bound hydrogen species, together with associated anions, persist in the interfacial region despite compressive loading and effectively decrease the adhesion (as compared to the water reference) arising from attractive $\mathrm{VdW}$ forces. ${ }^{63,65} \mathrm{We}$ expected that substantial amounts of surface-bound DAs should further decrease the measured pull-off forces in comparison with the smaller $\mathrm{Cl}^{-}$anions in $\mathrm{pH}$-control experiments. This was observed for malonic acid C3 (adhesion was lower than for the corresponding inorganic $\mathrm{pH} 2.0$
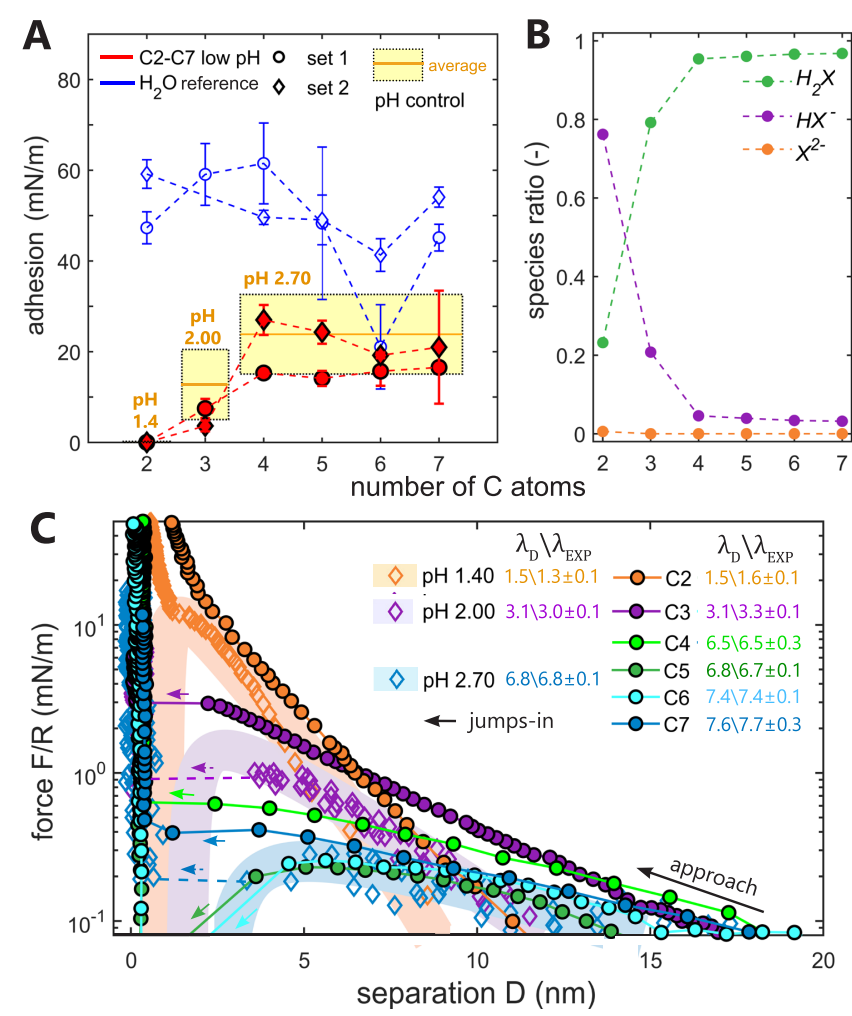

Figure 3. Forces measured in low-pH DA solutions ( $50 \mathrm{mM})$. (A) Adhesion (pull-off force) as a function of a number of carbon atoms C. For each acid, a new set of mica surfaces was used, and experiments were performed in duplicate (sets 1 and 2). Adhesion in MilliQ water is shown as a reference (and was measured in the same contact as in a given DA solution in each experiment). Yellow-shaded areas show adhesion in inorganic control solutions at a corresponding $\mathrm{pH}(\mathrm{pH}$ 1.40 for $\mathrm{C} 2,2.00$ for $\mathrm{C} 3$, and 2.70 for $\mathrm{C} 4-\mathrm{C} 7$; adjusted with $\mathrm{HCl}$ ). The orange center lines show the average measured adhesion for each $\mathrm{pH}$ control solution, and the box thicknesses represent the standard deviation of the measured adhesion; (B) speciation of DA in low-pH solutions used in $\mathrm{A}$, calculated in PhreeqC software using dissociation constants summarized in Table S5 ( $X$ is an organic anion); (C) representative force-distance curves measured on approach corresponding to the data shown in panel A. Forces measured in inorganic $\mathrm{pH}$-control solutions are marked with empty symbols along with corresponding DLVO fits (shaded areas; the areas were made thicker for better visibility; the Hamaker constant used was $\left.2.2 \times 10^{-20} \mathrm{~J}^{73}\right)$. Theoretical $\left(\lambda_{\mathrm{D}}\right)$ and experimental $\left(\lambda_{\mathrm{EXP}}\right)$ Debye lengths are indicated for all curves. DLVO calculations along with fitted surface potentials are shown in Supporting Information; Table S7, eqs S1-S3.

control), and for oxalic acid C2 (no adhesion compared to very small adhesion in pH 1.4 control). For larger DAs C4-C7, at higher $\mathrm{pH} 2.7$, this effect was less evident: the measured pulloff forces were only slightly lower than for the inorganic $\mathrm{pH}$ control. These findings are in line with the previous analysis of $\mathrm{HP}$ shifts: it is more likely that charged $\mathrm{HX}^{--} \mathrm{DA}$ species (abundant for C3 and C2; see DA speciation in Figure 3B) adsorb more strongly onto mica surfaces (slightly positively charged at low $\mathrm{pH}$ ) than dominantly neutral $\mathrm{C} 4-\mathrm{C} 7$ molecules. No effect of the increasing DA chain length on adhesion for $\mathrm{C} 4-\mathrm{C} 7$ again points to very weak adsorption of neutral DAs at low $\mathrm{pH}$.

Forces at higher separations $(\mathrm{D}>3 \mathrm{~nm}$ ) provide information about the structure of the diffuse layer part of EDL and allow us to estimate the mica surface potential in a given solution. ${ }^{70}$ Full force-distance profiles measured 

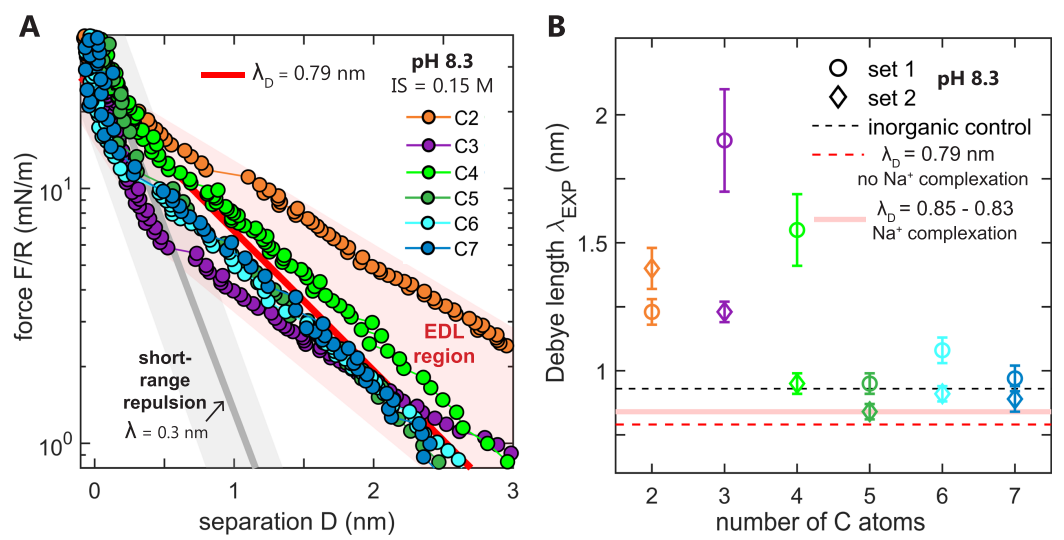

Figure 4. Force measurements in high-pH (8.2-8.4) DA solutions; $\mathrm{pH}$ adjusted with $\mathrm{NaOH}$. (A) Representative force-distance curves (set 2 ) measured on approach. Forces were repulsive in all high-pH DAs, but inorganic control $(\mathrm{NaCl}$; $\mathrm{pH} 8.3, \mathrm{IS}=0.15 \mathrm{M})$ showed small adhesion (pulloff force $=3.2 \pm 1.5 \mathrm{mN} / \mathrm{m}$; Figure S1). Ionic strength (IS) assuming no $\mathrm{Na}^{+}$complexation by DA was $0.15 \mathrm{M}$, and $\sim 0.13 \mathrm{M}^{\text {correcting for } \mathrm{NaX}}{ }^{-}$ complexes, where $\mathrm{X}^{-2}$ is a fully dissociated DA anion (see Table S6); the red line indicates the DLVO fit for the inorganic control (IS $=0.15 \mathrm{M}$ $\mathrm{NaCl}$ ) with a theoretical Debye length $\left(\lambda_{\mathrm{D}}\right)=0.79 \mathrm{~nm}$ and a fitted surface potential $\psi_{0}=-50 \mathrm{mV}$, see eq S1. Grey line marks additional repulsive force components at $\mathrm{D}<1 \mathrm{~nm}$, with exponential decay of $\sim 0.3 \mathrm{~nm}$. Shaded areas mark EDL repulsion and short-range repulsive regions for readability; (B) experimental Debye lengths $\left(\lambda_{\mathrm{EXP}}\right)$ measured on approach in DA solutions shown in panel A as a function of a number of carbon atoms in DA molecules. $\lambda_{\text {EXP }}$ were fitted in the EDL region $(D>2 \mathrm{~nm})$. For each DA, forces were measured with a new set of mica surfaces. The black dashed line shows average experimental $\lambda_{\mathrm{EXP}}$ for the control measurements in $\mathrm{NaCl}(\mathrm{pH} 8.3, \mathrm{IS}=0.15 \mathrm{M})$. The red dashed line corresponds to theoretical $\lambda_{\mathrm{D}}$ at IS $=0.15 \mathrm{M}$ (Eq S3), and the pink shaded area shows theoretical $\lambda_{\mathrm{D}}$ corrected for $\mathrm{Na}^{+}$complexation by DA (see Table S6 with the used association constants).

between two mica surfaces in DAs and $\mathrm{pH}$-control solutions on approach in low-pH solutions are plotted in Figure 3C. For C4-C7 DA solutions, the ionic strength was very low $(\sim 2$ $\mathrm{mM}$ ), and we measured a weak EDL repulsion followed by an adhesive VdW jump-in. The measured repulsion corresponds to low mica surface potentials, $\psi_{0}$, of 26 to $37 \mathrm{mV}$, depending on DA; see Table S7 and eqs S1-S3. For these larger DAs, there were no short-range steric repulsive components at small separations close to HPs. C3 malonic acid solutions, with a higher ionic strength of $\sim 10 \mathrm{mM}$, displayed correspondingly stronger EDL repulsion $\left(\psi_{0} \sim 55 \mathrm{mV}\right)$. Pronounced EDL repulsion with high fitted $\psi_{0}$ of $\sim 88 \mathrm{mV}$ was measured in the presence of C2 oxalic acid (IS $\sim 40 \mathrm{mM}$ ) followed by shortrange steric repulsion at small separations $<2 \mathrm{~nm}$.

Forces measured in DA solutions show quite good agreement with the corresponding $\mathrm{pH}$-control runs in terms of fitted surface potentials and Debye lengths (indicated in Figure 3C and Table S7) and can be quite well described with the DLVO theory. ${ }^{70}$ As the fitted surface potentials for DA solutions were very close to the ones measured in $\mathrm{HCl}$, we may exclude the strong, inner-sphere bonding of DAs on mica surfaces suggested previously for kaolinite ${ }^{24}$ because DA surface complexation would have strongly affected the measured repulsion and fitted $\psi_{0}$. Neutral DA species did not influence the measured forces to any observable extent. The short-range nonDLVO steric repulsion evidenced at small separations $(\mathrm{D}<2 \mathrm{~nm})$ in $\mathrm{C} 2$ and low $\mathrm{pH} 1.4$ control was related to the surface structure formed by proton-bonded anions, ${ }^{63}$ as discussed previously.

Previous batch adsorption experiments generally point to higher amounts of clay-adsorbed DAs at low $\mathrm{pH}^{23,24}$ Many studies have attributed this $\mathrm{pH}$-dependent phenomenon to amphoteric hydroxyl groups at clay edges, which are positively charged at low $\mathrm{pH} .{ }^{1,21,25,26}$ However, our results highlight the importance of the negatively charged basal mica surfaces, which also display $\mathrm{pH}$-dependent behavior. Although these surfaces have permanent negative charge because of structural ionic substitutions, ${ }^{38}$ the adsorbed hydrogen species still significantly affect the diffuse double layer potential as they screen the mica surface charge at $\mathrm{pH} \sim 3-4^{64,67}$ and contribute to positive surface potentials at lower $\mathrm{pH}$ values. Although under natural conditions the ratio between basal surfaces and broken edge surfaces may be very variable, basal planes can also act as important, $\mathrm{pH}$-dependent bonding sites for organics. This is in line with the findings of Newcomb et al., ${ }^{27}$ who showed $\mathrm{pH}$-dependent binding of $-\mathrm{COOH}$ functional groups to mica basal surfaces.

Repulsive Forces Measured in the Presence of $\mathrm{Na}^{+}$. Forces measured in $\mathrm{pH}$ 8.3 DA solutions (with fully dissociated organic anions) were always repulsive, both on approach (as shown in Figure 4A) and on retraction. At this high ionic strength (IS $\sim 0.15 \mathrm{M}$ ), the EDL is significantly screened, and we could detect relatively strong repulsive EDL forces only at small separations, $\mathrm{D}<3 \mathrm{~nm}$. At even smaller distances, $\mathrm{D}<1 \mathrm{~nm}$, we measured an additional short-range repulsion with small decay lengths of $\sim 0.3-0.5 \mathrm{~nm}$, as shown in Figure 4A. This steric repulsion can be explained solely by the dehydration of $\mathrm{Na}^{+}$bound as the outer-sphere and hydrated species in the Stern layer, ${ }^{62,68}$ as it was also measured for the $\mathrm{pH} 8.3 \mathrm{NaCl}$ control experiment with the same ionic strength as the DA solutions.

However, in contrast to DAs, forces measured in the high$\mathrm{pH} \mathrm{NaCl}$ control exhibited a small adhesion (pull-off force of $=$ $3.2 \pm 1.5 \mathrm{mN} / \mathrm{m}$; Figure S1). The stronger repulsion for DA solutions than in the controls can be explained by the presence of divalent DA anions (only $\sim 25 \%$ of DA anions are associated with $\mathrm{Na}$ as $\mathrm{NaX}^{-}$complexes $^{74}$ ) as predicted by the DLVO theory (disjoining pressures are generally higher at a given separation for $1: 2$ vs $1: 1$ electrolyte with the same IS $^{75}$ ). Alternatively, if DAs associate with $\mathrm{Na}^{+}$in the interlayer region, the steric hydration repulsion might have been stronger in the presence of these complexes than for $\mathrm{Na}^{+}$alone in the $\mathrm{NaCl}$ $\mathrm{pH}$-control experiment. This is in line with the findings of Kobayashi et al. (2017), ${ }^{72}$ who demonstrated indirect 

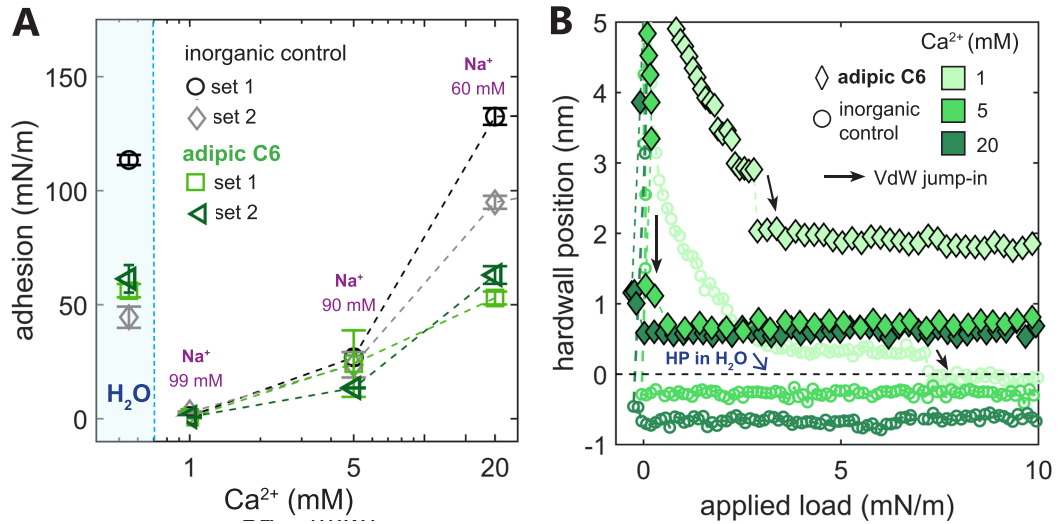

Figure 5. (A) Adhesion (pull-off force) measured in high-pH (8.3) adipic acid (C6) solutions as a function of $\mathrm{Ca}^{2+}$ concentration ( $\mathrm{pH}$ adjusted with 1, 5, and $20 \mathrm{mM}$ of $\mathrm{Ca}(\mathrm{OH})_{2}$ and further with $\mathrm{NaOH}$ to $\mathrm{pH}$ 8.3-8.4; see solution parameters in Table S3). Circle and diamond symbols represent control measurements without added DA but with the same content of $\mathrm{Ca}^{2+}$ and the same ionic strength. The blue-shaded region on the left side on the plot shows the reference adhesion force measured in pure MilliQ water at the beginning of each experiment; (B) the hardwall position as a function of applied load corresponding to the measurements shown in subplot A. Only measurements on approach are shown. HPs for each representative force measurement were shifted so that the HP measured initially in water was located at $0 \mathrm{~nm}$ to facilitate the comparison between different pairs of micas. The arrows mark attractive VdW jump-in instabilities.

adsorption of carboxylic acids via water bridging between deprotonated $-\mathrm{COO}^{-}$and $\mathrm{Na}^{+}$adsorbed on the mica surface. Stronger repulsion between illite clay particles at basic $\mathrm{pH}$ (8.5) in the presence of oxalate anions (C2) and $\mathrm{Na}^{+}$than in $\mathrm{NaCl}$ solutions of the same IS has been observed by Jiang et al. $(2012)^{52}$ in batch colloidal stability experiments. Interestingly, the authors measured a very similar aggregation behavior both at low (5.5) and high (8.5) $\mathrm{pH} \mathrm{Na}$-oxalate solutions despite the possible stronger inner-sphere complexation of DA anions at edge surface sites at low $\mathrm{pH}$. This suggest that oxalate can also bind effectively to clay surfaces at higher $\mathrm{pH}$ values, pointing to likely adsorption of oxalate on the basal clay surfaces at high $\mathrm{pH}$ and in the presence of $\mathrm{Na}^{+}$. Higher, $\mathrm{Na}^{+}$induced adsorption of humic acid onto clays has been also observed by Rashid et al. ${ }^{30}$ in batch adsorption experiments and attributed to higher proportion of humic acid bonded via $\mathrm{VdW}$ forces because of more pronounced EDL screening at higher ionic strengths.

Figure 4A also shows forces measured at larger separations, in the EDL region. The forces are in quite good agreement with DLVO theory despite of the high ionic strength of the DA solutions (IS $\sim 0.15 \mathrm{M}$, see Table S8). Fitted Debye lengths $\left(\lambda_{\text {EXP }}\right)$ plotted in Figure $4 \mathrm{~B}$ are only slightly larger than the theoretical Decay lengths $\left(\lambda_{\mathrm{D}}\right)$ calculated based on the ionic strengths (IS; see eq S3), especially for C4-C7 DAs. The repulsive forces that we measured were strong, with the fitted surface potentials $\psi_{0}$ of -65 to $-85 \mathrm{mV}$ (we did not fit the surface potentials very precisely as used solutions are mixtures of mono and divalent cations and anions, ${ }^{70}$ see eq $\mathrm{S} 1$ ), which agrees with the poor charge-screening properties of hydrated $\mathrm{Na}^{+}$counterions. ${ }^{66}$ Larger Debye lengths $\left(\lambda_{\text {EXP }}\right)$ measured for $\mathrm{C} 2$ and C3 DAs might likely point to additional repulsive force components related to stronger adsorption of these two smallest DAs. Stronger sorption of oxalate in contrast to other carboxylic acids has been also reported for kaolinite by Ward \& Brady. ${ }^{50}$

$\mathrm{Ca}^{2+}$-Promoted Attractive Forces. Because $\mathrm{Ca}^{2+}$ forms much stronger complexes with carboxylic groups of organic molecules than monovalent ions such as $\mathrm{Na}^{+}, \mathrm{Ca}^{2+}$ is known to affect the adsorption of organic species onto mineral surfaces in a major way, most often by forming cation bridges between two negative charges. ${ }^{21,23,33,40,42}$ Moreover, $\mathrm{Ca}^{2+}$ significantly impacts clay aggregation in inorganic systems. ${ }^{7,77} \mathrm{We}$ therefore re-examined forces acting between mica surfaces at high $\mathrm{pH}$ in the presence of varying amounts of $\mathrm{Ca}^{2+}$ both in DA solutions (with $\mathrm{pH}$ adjusted with $\mathrm{NaOH}$ and partially with $\left.\mathrm{Ca}(\mathrm{OH})_{2}\right)$ and in inorganic $\mathrm{NaCl}-\mathrm{CaCl}_{2}$ control solutions with the same Ca:Na ratio (see Table S3). The formation of complexes is prevalent at high $\mathrm{pH}$, when DAs are fully dissociated $^{71,78-80}$ (see Table S6).

Figure 5A shows the comparison of pull-off forces measured in inorganic control and $\mathrm{C} 6$ adipic acid solutions at high $\mathrm{pH}$ in the presence of $\mathrm{Ca}^{2+}$. In all cases, the measured adhesion increased with the increasing $\mathrm{Ca}^{2+}$ concentration. Even $1 \mathrm{mM}$ of $\mathrm{Ca}^{2+}(\mathrm{Ca}: \mathrm{Na}=1: 99)$ was sufficient to induce adhesion (pull-off forces $<1 \mathrm{mN} / \mathrm{m}$ ) between mica surfaces (in contrast to the repulsive forces measured in high-pH DA solutions with $\mathrm{Na}^{+}$as the only inorganic cation). This stronger attraction was also evidenced by small VdW jump-in instabilities measured on approach for all solutions (Figure 5B). Although similar correlations between pull-off force and $\mathrm{Ca}^{2+}$ concentration could be observed both for inorganic control and DA solutions, the adhesion between mica surfaces was lower in the presence of organic anions. This effect became especially evident at higher $\mathrm{Ca}^{2+}$ concentrations (Figure 5A).

Mica surfaces are known to attract each other strongly in the presence of $\mathrm{Ca}^{2+}$ ions because divalent ions, both residing in the diffuse layer and adsorbed onto the surface, screen the negative surface charge of mica very efficiently. This effect is especially pronounced at $0.01-0.1 \mathrm{M} \mathrm{Ca}^{2+}$ concentrations, at which surface charge can be almost completely screened by counterions, leaving attractive $\mathrm{VdW}$ forces to dominate at all surface separations. ${ }^{77}$ Parsons and Ninham $(2010)^{74}$ determined that the negative mica surface charge is neutralized at $\mathrm{Ca}^{2+}$ concentrations as low as $20 \mathrm{mM}$ in $\mathrm{Ca}\left(\mathrm{NO}_{3}\right)_{2}$ solutions. In addition, ion correlation forces between surface adsorbed $\mathrm{Ca}^{2+}$ are known to further enhance attractive forces between mica surfaces at separations $<3 \mathrm{~nm} .^{76,77}$ This is in line with our findings, as the double layer repulsion was measurable at $1 \mathrm{mM}$ $\mathrm{Ca}^{2+}$ (see forces plotted for surface separations $<5 \mathrm{~nm}$ in Figure 5B), but barely detectable for 5 and $20 \mathrm{mM} \mathrm{Ca}^{2+}$ concentrations, both in inorganic control experiments and in 

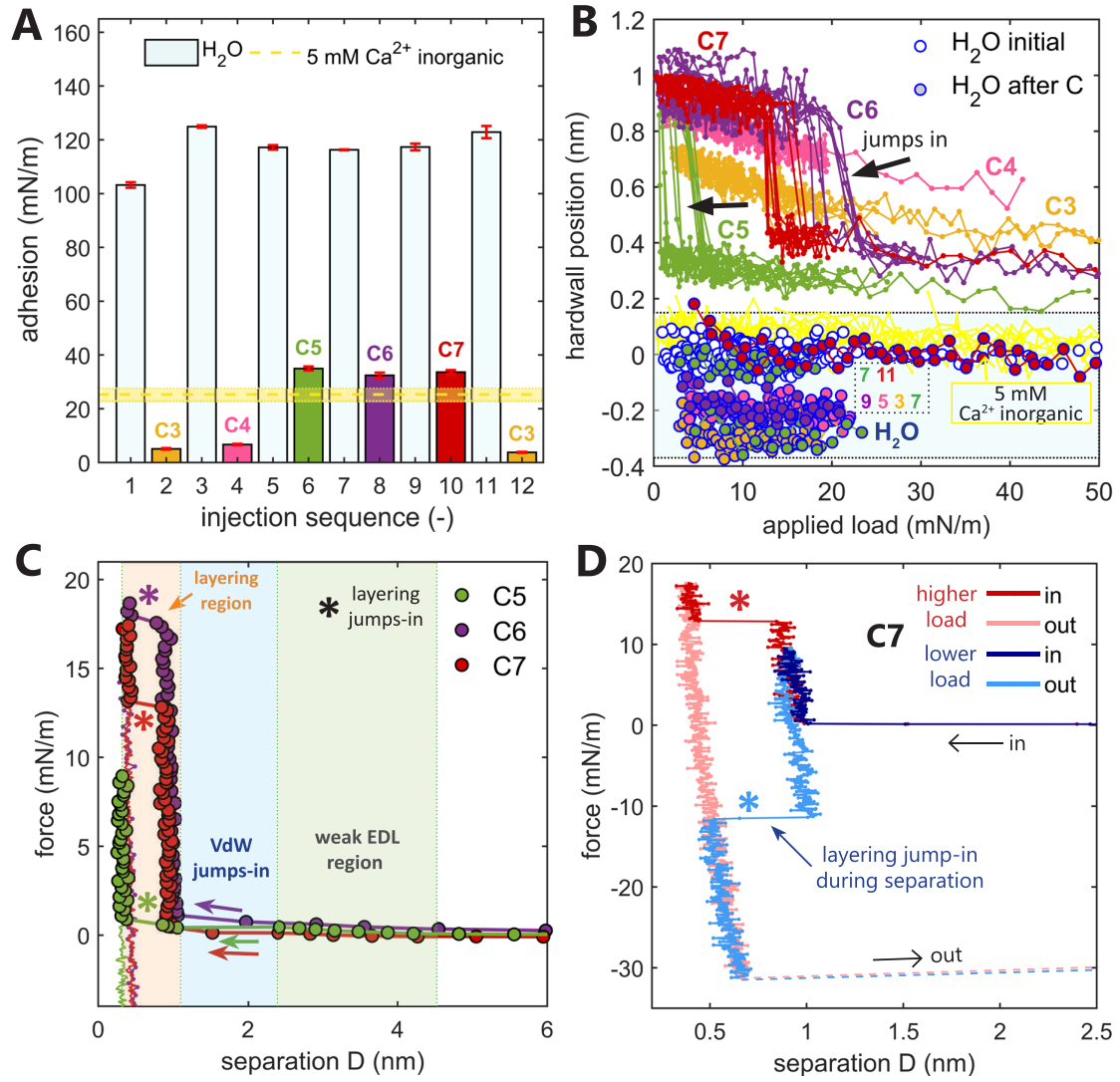

Figure 6. Forces measured in $\mathrm{pH} 8.3 \mathrm{DA}$ solutions with $5 \mathrm{mM} \mathrm{Ca}^{2+}$. $\mathrm{pH}$ was adjusted with $\mathrm{Ca}(\mathrm{OH})_{2}$ and further to 8.3 with $\mathrm{NaOH}($ see the solution composition in Table S4); (A) Adhesion (pull-off forces) measured in MilliQ water and in C3-C7 DA solutions shown in the order of solution injection. All forces were measured in the same contact region between mica surfaces. Adhesion in $\mathrm{H}_{2} \mathrm{O}$ did not vary, indicating a lack of strong adsorption of DAs onto mica surfaces, irrespective of the DA carbon chain length. Error bars show pull-off force variation in minimum five consecutive force-runs for each solution. Pull-off forces measured in the inorganic $5 \mathrm{mM} \mathrm{Ca}{ }^{2+} \mathrm{NaCl}$ experiment with the same Ca:Na ratio are indicated with the yellow line (the dashed yellow line shows the average value, and the shaded area is standard deviation); (B) hardwall positions as a function of applied load corresponding to the measurements shown in subplot A. Only force-distance curves on approach are displayed. All HPs are plotted with respect to the HP initially measured in $\mathrm{H}_{2} \mathrm{O}$, which was set to $0 \mathrm{~nm}$ at maximum load. $\mathrm{HPs}$ measured in all $\mathrm{H}_{2} \mathrm{O}$ runs (blue-shaded area) were the smallest (the injection sequence is indicated with numbers, and two HPs are marked for the seventh injection as the HP in this solution slightly changes over the course of experiment because of instrumental drift or slower desorption of organic acids). HPs in C3-C7 solutions were always measured at larger separations; (C) layering, VdW, and EDL regions shown for representative forces measured as a function of surface separation in C5-C7 DA solutions corresponding to the data shown in subplot B; (D) comparison of layering features in C7 DA solution for forces measured with high (red) and low (blue) applied load. Similar behavior was also observed for C6.

C6 adipic acid solutions. Moreover, the adhesion in $20 \mathrm{mM}$ $\mathrm{Ca}^{2+}$ was enhanced with respect to water (Figure 5A).

Effect of $\mathrm{Ca}^{2+}$ on Binding of Dicarboxylic Anions to Mica Surfaces. The decrease in pull-off forces in comparison with the inorganic controls observed in adipic acid solutions (Figure 5A) suggests that the mica surface composition was influenced by the presence of C6 anions. This effect could have been simply related to the reduced amount of free $\mathrm{Ca}^{2+}$ because of complexation with $-\mathrm{COO}^{-}$groups of adipic acid and thus a smaller amount of $\mathrm{Ca}^{2+}$ accessible for adsorption onto mica surfaces. The association between $\mathrm{Ca}^{2+}$ and $\mathrm{C} 6$ is rather strong ${ }^{79}$ (see Table S6), and PhreeqC modeling ${ }^{81}$ indicates that $\sim 50 \%$ of the bulk $\mathrm{Ca}^{2+}$ is bound with $\mathrm{C} 6$ anions as neutral $\mathrm{CaH}_{8} \mathrm{C}_{6} \mathrm{O}_{4}$ species for all $\mathrm{Ca}^{2+}$ concentrations. The formation of positively charged $\mathrm{CaH}_{9} \mathrm{C}_{6} \mathrm{O}_{4}^{+}$in the bulk is negligible. ${ }^{71,78}$ As the bulk solution speciation modeling does not consider any surface specific effects, it is likely that adipic acid could complex with excess surface-adsorbed $\mathrm{Ca}^{2+}$ via cation bridging. ${ }^{52,72}$ Coions within a diffuse layer region are generally expected to have a major effect on the interfacial structure if the counterions have very efficient surface charge screening properties (as in the case of $\mathrm{Ca}^{2+}$ or $\mathrm{Cs}^{+}$but not poorly charge-screening $\left.\mathrm{Na}^{+}\right) .{ }^{66}$ In our work, the interpretation of enhanced adsorption of adipic acid anions in the EDL, facilitated by surface-bound $\mathrm{Ca}^{2+}$, is further supported by a pronounced shift of the hardwall positions to larger separations in all C6 solutions (in comparison with the inorganic control experiments having the same $\mathrm{Ca}: \mathrm{Na}$ ratio, but $\mathrm{Cl}^{-}$as anions), as plotted in Figure 5B. We therefore suggest that adipic anions are likely to bind electrostatically to mica surfaces via $\mathrm{Ca}^{2+}$ cation links and that the lower adhesion measured in C6 solutions was due to adipic acid anions complexation both in the bulk and in the interfacial region.

We further examined forces acting between mica surfaces in the presence of $5 \mathrm{mM} \mathrm{Ca}^{2+}$ for all C3-C7 DAs (Figure 6; C2 could not be used because of the immediate precipitation of calcium oxalate). This time, however, we used the same pair of mica surfaces to compare adhesion and possible binding of DAs for all C3-C7 anions. To assess the stability of DA adsorption, we rinsed the surfaces thoroughly with MilliQ water and measured forces in water after each used DA solution, as shown in Figure 6A (the solution injection 
sequence is indicated on the $x$-axis). The adhesion measured in DA solutions was in all cases lower than that in water, with the smallest pull-off forces in $\mathrm{C} 3$ and $\mathrm{C} 4$ solutions. For these two DAs, the adhesion was also weaker than that in the inorganic control experiment, suggesting stronger adsorption/complexation of $\mathrm{C} 3$ and $\mathrm{C} 4$ dicarboxylic anions on mica surfaces than for the larger $\mathrm{C} 5-\mathrm{C} 7$ DAs. The bulk $\mathrm{Ca}^{2+}$ association constants ( $\mathrm{CaX}$ complexes) for all DAs are comparable (e.g., $\mathrm{pK}_{\mathrm{a}}=2.24$ for $\mathrm{C}^{71}$ and $\mathrm{pK}_{\mathrm{a}}=2.19$ for $\mathrm{C} 6{ }^{79}$ see Table S6). As such, the differences in bulk $\mathrm{Ca}^{2+}$ complexation cannot explain more than two times lower adhesion measured in C3-C4 than in C5-C7. Most likely, the variation in the measured pull-off forces was related to stronger binding of smaller C3 and C4 anions onto mica surfaces.

Stronger binding of smaller DA anions is additionally supported by HP shifts plotted as a function of applied normal load in Figure 6B: At loads $>20 \mathrm{mN} / \mathrm{m}$, shift in HPs generally follows the adhesion values (shown in Figure 6A) as largest $\mathrm{HP}$ shifts to higher separations were measured for C4 and C3 DAs, and smaller HP shifts were measured for C5-C7 DAs. This indicates that adsorption of $\mathrm{C} 3$ and $\mathrm{C} 4 \mathrm{DAs}$ prevented mica surfaces from coming into direct contact to a larger extent. Interestingly, at loads $<20 \mathrm{mN} / \mathrm{m}$, forces measured for the most adhesive C5-C7 DAs displayed distinct layering features that were not related to attractive VdW forces (VdW jumps-in are measured at larger separations, see Figure $6 \mathrm{C}$ ). Figure $6 \mathrm{~B}$ shows explicit layering for C6 and C7 DAs (as reproducible 5 $\AA$ jumps-in), while for C5, similar layering features were observed at smaller applied load (Figure 6C). We interpret these sudden attractive jumps-in as squeezing-out events, during which adsorbed molecular layers of DAs are removed from the contact region. Because we did not observe such features in inorganic control experiments, the squeezed layers must have been composed of DA molecules. After the jump-in events, the HPs still remained substantially shifted with respect to the water reference (Figure 6B). This suggest that DAs were not fully displaced from the interlayer. As we measured jumpsin only for the largest, more hydrophobic DAs, it seems plausible that the squeeze-out events corresponded to the removal of outer DA layers, which were bound to the surfaceadsorbed DA molecules by weak hydrophobic interactions between aliphatic backbone chains of the DA molecules in a self-assembly fashion. The first layers of DAs were instead adsorbed on mica surfaces electrostatically via $\mathrm{Ca}^{2+}$ cation bridges.

The intermediate runs in $\mathrm{H}_{2} \mathrm{O}$ after each DA helped us to assess the strength of the adsorption of DAs onto mica surfaces in the presence of $\mathrm{Ca}^{2+}$ (Figure 6). Figure 6A shows that pulloff forces in $\mathrm{H}_{2} \mathrm{O}$ always went back to a similar level $(\sim 120$ $\mathrm{mN} / \mathrm{m}$ ) after measurements in each DA solution, indicating that the adsorption of DAs was weak, because DAs could be easily rinsed away from the mica surfaces by water. This is further evidenced by the $\mathrm{HPs}$ in $\mathrm{H}_{2} \mathrm{O}$, which were always measured at smaller distances $(\sim 1 \mathrm{~nm}$ less $)$ than HPs in DA solutions (Figure 6B). As such, DA anions are most likely adsorbed onto mica surfaces by relatively weak electrostatic forces via $\mathrm{Ca}^{2+}$ cation bridging (such indirect adsorption is weak as the bridging $\mathrm{Ca}^{2+}$ cations remain hydrated ${ }^{82}$ ). In addition, larger DAs can be further adsorbed by even weaker hydrophobic chain interactions with the first, surface-bound DA layers.

Hydrophobic Effects. Adsorption of outer layers of C6 and $\mathrm{C} 7$ dicarboxylic molecules, which bind to the first layer of
DAs (adsorbed on mica basal surfaces via $\mathrm{Ca}^{2+}$ cation bridges) through hydrophobic assembly of aliphatic chains, can be further supported by the unstable character of DA molecules trapped in the interlayer region as illustrated in Figure 6D: when we compressed mica surfaces to loads just below the level for attractive jump-ins and immediately started to separate the surfaces, the same $5 \AA$-thick layer was still displaced from the contact region, but now minutes later, during retraction (as evidenced by a jump-in during decompression). This indicates that the layer of DA molecules was thermodynamically unstable at a given separation but required some time to diffuse out of the contact region when not aided by the movement of the compressing surface. These layers could have been likely composed of neutral $\mathrm{CaX}$ complexes, explaining their weak hydrophobic binding to the first layer of electrostatically adsorbed DA molecules in the interlayer region. We did not observe such events for smaller C5 DA, which had layering detected at lower applied load. Interestingly, although binding of smaller C3 and C4 DAs to mica seems stronger (as indicated by lower adhesion values; see Figure 6A), the adsorbed amount of more hydrophobic C5-C7 DAs may be larger because of the observed multilayer adsorption via assembly of hydrophobic chains. The binding of excess DAs via hydrophobic interactions with the first layer of adsorbed organic molecules on the kaolinite surface has been also suggested by Kang and Xing (2007), ${ }^{23}$ who observed a higher amount of adsorbed longer-chained than shorterchained DAs.

We did not detect any layering features for the smaller C3 and $\mathrm{C} 4 \mathrm{DAs}$ within the used range of applied loads $(<50 \mathrm{mN} /$ $\mathrm{m}$; Figure $6 \mathrm{~B}$ ). These two DAs showed a continuous decrease of the HP with stronger compression, suggesting progressive squeezing out of the surface adsorbed organic species from the interlayer region. The squeezing-out process gives rise to shortrange repulsion as energy is required to displace the adsorbed molecules from the contact region. Repulsive forces were stronger for $\mathrm{C} 3$ and $\mathrm{C} 4$ than for C5-C7 DAs, as evidenced by the absence of layering at loads $<50 \mathrm{mN} / \mathrm{m}$. In contrast, no short-range repulsion was present for the measurements in $\mathrm{H}_{2} \mathrm{O}$ between each DA solution, as reflected by the negligible change in HPs despite the increasing applied load (blueshaded area in Figure 6B).

Implications for Clay Aggregation. Our SFA force measurements provided face-specific information about attractive and repulsive interactions between muscovite basal surfaces in the presence of $-\mathrm{COOH}$-laden DAs and two soilabundant cations, $\mathrm{Na}^{+}$and $\mathrm{Ca}^{2+}$. The inorganic cations showed a contrasting effect both on forces and on DA adsorption: Monovalent $\mathrm{Na}^{+}$promoted repulsive interactions between mica surfaces and did not significantly enhance adsorption of DAs onto basal plane mica surfaces. On the other hand, divalent $\mathrm{Ca}^{2+}$ induced not only strong attractive forces between mica surfaces but also facilitated binding of DAs by cation bridges. Thus, $\mathrm{Ca}^{2+}$ provides binding sites even for highly soluble, low-molecular-weight organics with $-\mathrm{COOH}$ functionalities, while $\mathrm{Na}^{+}$does not facilitate their substantial adsorption. We showed that even very small $\mathrm{Ca}: \mathrm{Na}$ ratios are sufficient to reduce EDL repulsion and induce adhesion between mica surfaces, pointing to preferential adsorption of $\mathrm{Ca}^{2+}$ on mica surfaces. Furthermore, in the absence of other cations, $\mathrm{H}_{3} \mathrm{O}^{+}$species at low $\mathrm{pH}$ can cause mica charge reversal and lead to electrostatic adsorption of anionic DAs. These findings underline the importance of charge screening ions for 
face-face clay aggregation and for adsorption of negatively charged organic species onto clay surfaces: Although clay faces have strong negative structural surface charge, it is the remaining surface potential in the Stern layer, unscreened by cations, that will determine aggregation and binding capacities of the basal plane clay surfaces.

$\mathrm{Ca}^{2+}$ has an intricate effect on clay-organic matter binding. Our results showed that even a small proportion of calcium ions with respect to sodium can cause strong aggregation of clay particles, while organic species counteract this effect by adsorbing to surface-bound $\mathrm{Ca}^{2+}$. Other studies suggest that calcium-promoted adsorption of organic molecules may even drive complete disaggregation provided that the organic species diffuse into the aggregates and render clay surfaces negatively charged, or if their strong adsorption induces steric repulsion between clay platelets. ${ }^{6,45,46,83,84}$ At high $\mathrm{Ca}^{2+}$ concentrations, both organic molecules and clay surfaces may become positively charged because of excess calcium binding, making $\mathrm{Ca}^{2+}$ bridges ineffective and preventing any adsorption of organic molecules onto clay surfaces altogether, as observed for polycarboxylate molecules by Wu et $\mathrm{al}^{85}$ Thus, the degree of $\mathrm{Ca}^{2+}$-induced aggregation will be largely sensitive to $\mathrm{Ca}^{2+}$ concentration, complexation strength, speciation, surface charge, and other environmental factors. Conversely, inert cations, such as $\mathrm{Na}^{+}$, may induce more severe disruption of organoclay aggregates. ${ }^{27,86}$

In all cases, we measured only weak and reversible adsorption of DAs from aqueous media onto mica surfaces. This is in line with previous studies suggesting that small dicarboxylic or carboxylic acids adsorb to clay surfaces dominantly as outer sphere, weakly bound species. ${ }^{21-24}$ Our results indicate that even in the presence of $\mathrm{Ca}^{2+}$, the surfaceadsorbed DAs could be easily removed, simply by rinsing the surfaces with water. This in line with other studies that suggest that higher-molecular-weight organic species with multiple reactive functional groups can adsorb onto clay mineral surfaces with a higher affinity and in a more stable way, and are more important for the formation of clay-organic matter aggregates. ${ }^{20}$ Strong sorption of organic species onto clays may be also conditioned by wetting-drying cycles in soils, with weaker adsorption from the aqueous phase followed by stronger surface complexation during drying, as suggested by Kang and Xing $(2007)^{23}$ for sorption of DAs onto kaolinite and montmorillonite. Nevertheless, by resolving nanoscale forces acting between mica surfaces, we showed that even a small amount of adsorbed low-molecular-weight and highly soluble DAs with longer aliphatic chains can render basal clay surfaces more hydrophobic and significantly alter the surface properties of the basal clay surfaces.

\section{CONCLUSIONS}

Our face-specific SFA force measurements indicate that soluble DAs with varying degree of hydrophobicity adsorb on muscovite mica basal surfaces only by weak forces including electrostatic, hydrophobic, and likely hydrogen bonding. No inner-sphere bonding of DAs was detected, even at the lowest $\mathrm{pH}$. In low-pH solutions, major electrostatic adsorption of negatively charged oxalic and malonic acids was observed for positively charged, protonated mica surfaces. Neutral DAs (glutaric to pimelic) adsorbed at low $\mathrm{pH}$ to a minor extent, most likely by hydrogen bonding, as evidenced by little change in adhesion as compared to control experiments. At higher $\mathrm{pH}$, DA adsorption was affected by the type of background cations:
Forces measured in the presence of $\mathrm{Na}^{+}$suggest only minor, indirect binding of dicarboxylic anions onto mica surfaces, likely with higher adsorption measured for the smallest oxalate and malonate anions. $\mathrm{Ca}^{2+}$ promoted adsorption of dicarboxylic anions to a larger extent, via cation bridging. Our results show that calcium-induced DA anion binding was more efficient at higher $\mathrm{Ca}^{2+}$ concentrations ( 5 and $20 \mathrm{mM}$ ), at which the negative surface charge of mica was screened, and no double layer repulsion was detected. We additionally resolved multilayer adsorption of DAs via weak hydrophobic forces in the presence of $\mathrm{Ca}^{2+}$, however, only for the larger DAs with five to seven $\mathrm{C}$ atoms. In all cases, the adsorption of DAs led to a decrease in adhesive forces measured between basal mica surfaces. This finding indicates that even weak, outer-sphere adsorption of small organic molecules onto basal surfaces can decrease adhesion between clay particles. Our face-specific measurements underline that tetrahedral mica surfaces display variable surface charge in the presence of protons and inorganic cations, which facilitate binding of organic molecules onto these negatively charged surfaces to various extents. $\mathrm{Na}^{+}$ background cations demonstrate an adverse effect of monovalent cations on clay-organic aggregation. Conversely, divalent $\mathrm{Ca}^{2+}$ at moderate concentrations may promote organomineral aggregate formation.

\section{ASSOCIATED CONTENT}

\section{SI Supporting Information}

The Supporting Information is available free of charge at https://pubs.acs.org/doi/10.1021/acs.langmuir.0c02290.

Tabularized summary of previous relevant studies on organic acid-mineral interactions; solution parameters, DA dissociation and association constants; DLVO fitting parameters; and supplementary force measurements in control pH $8.3 \mathrm{NaCl}$ solution(PDF)

\section{AUTHOR INFORMATION}

\section{Corresponding Author}

Joanna Dziadkowiec - NJORD Centre, Department of Physics, University of Oslo, Oslo 0371, Norway; Institute of Applied Physics, Vienna University of Technology, 1040 Vienna, Austria; (1) orcid.org/0000-0001-6560-8744; Email: joanna.dziadkowiec@fys.uio.no

\section{Author}

Anja Røyne - NJORD Centre, Department of Physics, University of Oslo, Oslo 0371, Norway

Complete contact information is available at: https://pubs.acs.org/10.1021/acs.langmuir.0c02290

\section{Notes}

The authors declare no competing financial interest.

\section{ACKNOWLEDGMENTS}

J.D. acknowledges support from the Research Council of Norway, FRIPRO grant nr 286733 (Solid-solid interfaces as critical regions in rocks and materials: probing forces, electrochemical reactions, friction, and reactivity). This project has also received funding from the European Union Horizon 2020 research and innovation program under the Marie Skłodowska-Curie grant agreement no. 642976-Nano-Heal Project. This work reflects only the author's view, and the European Commission is not responsible for any use that may 
be made of the information it contains. We thank the anonymous reviewers for their insightful comments.

\section{REFERENCES}

(1) Kleber, M.; Eusterhues, K.; Keiluweit, M.; Mikutta, C.; Mikutta, R.; Nico, P. S. Mineral-organic associations: formation, properties, and relevance in soil environments. In Adv. in agron., Elsevier 2015, $130,1-140$.

(2) Anslyn, E. V.; Dougherty, D. A. Modern physical organic chemistry. University science books: 2006.

(3) Karavanova, E. Dissolved organic matter: Fractional composition and sorbability by the soil solid phase (review of literature). Eur. soil sci. 2013, 46, 833-844.

(4) Dagnelie, R. V. H.; Descostes, M.; Pointeau, I.; Klein, J.; Grenut, B.; Radwan, J.; Lebeau, D.; Georgin, D.; Giffaut, E. Sorption and diffusion of organic acids through clayrock: comparison with inorganic anions. J. hydrol. 2014, 511, 619-627.

(5) Imai, A.; Fukushima, T.; Matsushige, K.; Kim, Y. H. Fractionation and characterization of dissolved organic matter in a shallow eutrophic lake, its inflowing rivers, and other organic matter sources. Water Res. 2001, 35, 4019-4028.

(6) Philippe, A.; Schaumann, G. E. Interactions of dissolved organic matter with natural and engineered inorganic colloids: a review. Environ. Sci. Technol. 2014, 48, 8946-8962.

(7) Han, L.; Sun, K.; Jin, J.; Xing, B. Some concepts of soil organic carbon characteristics and mineral interaction from a review of literature. Soil Biol. Biochem. 2016, 94, 107-121.

(8) Wattel-Koekkoek, E.; Buurman, P.; Van Der Plicht, J.; Wattel, E.; Van Breemen, N. Mean residence time of soil organic matter associated with kaolinite and smectite. Eur. J.soil sci. 2003, 54, 269278.

(9) Torn, M. S.; Trumbore, S. E.; Chadwick, O. A.; Vitousek, P. M.; Hendricks, D. M. Mineral control of soil organic carbon storage and turnover. Nature 1997, 389, 170.

(10) Gu, B.; Mehlhorn, T. L.; Liang, L.; McCarthy, J. F. Competitive adsorption, displacement, and transport of organic matter on iron oxide: I. Competitive adsorption. Geochim. Cosmochim. Acta 1996, 60, 1943-1950.

(11) Illés, E.; Tombácz, E. The role of variable surface charge and surface complexation in the adsorption of humic acid on magnetite. Colloids Surf., A 2003, 230, 99-109.

(12) Filius, J. D.; Lumsdon, D. G.; Meeussen, J. C.; Hiemstra, T.; Van Riemsdijk, W. H. Adsorption of fulvic acid on goethite. Geochim. Cosmochim. Acta 2000, 64, 51-60.

(13) Tipping, E.; Cooke, D. The effects of adsorbed humic substances on the surface charge of goethite $(\alpha-\mathrm{FeOOH})$ in freshwaters. Geochim. Cosmochim. Acta 1982, 46, 75-80.

(14) Guan, X.-H.; Shang, C.; Chen, G.-H. Competitive adsorption of organic matter with phosphate on aluminum hydroxide. J. Colloid Interf. Sci. 2006, 296, 51-58.

(15) Zhang, L.; Luo, L.; Zhang, S. Integrated investigations on the adsorption mechanisms of fulvic and humic acids on three clay minerals. Colloids Surf., A 2012, 406, 84-90.

(16) Zhou, J. L.; Rowland, S.; Fauzi, R.; Mantoura, C.; Braven, J. The formation of humic coatings on mineral particles under simulated estuarine conditions-a mechanistic study. Water Res. 1994, 28, 571579.

(17) Sørensen, L. H. Stabilization of newly formed amino acid metabolites in soil by clay minerals. Soil Sci. 1972, 114, 5-11.

(18) Lützow, M. V.; Kögel-Knabner, I.; Ekschmitt, K.; Matzner, E.; Guggenberger, G.; Marschner, B.; Flessa, H. Stabilization of organic matter in temperate soils: mechanisms and their relevance under different soil conditions-a review. Eur. J. soil sci. 2006, 57, 426-445.

(19) Throckmorton, H. M.; Bird, J. A.; Monte, N.; Doane, T.; Firestone, M. K.; Horwath, W. R. The soil matrix increases microbial C stabilization in temperate and tropical forest soils. Biogeochemistry 2015, 122, 35-45.

(20) Labille, J.; Thomas, F.; Milas, M.; Vanhaverbeke, C. Flocculation of colloidal clay by bacterial polysaccharides: effect of macromolecule charge and structure. J. Colloid Interf. Sci. 2005, 284, $149-156$.

(21) Liu, X.; Lu, X.; Zhang, Y.; Zhang, C.; Wang, R. Complexation of carboxylate on smectite surfaces. Phys. Chem. Chem. Phys. 2017, 19, $18400-18406$.

(22) Xue, X.; Xu, Z.; Pedruzzi, I.; Li, P.; Yu, J. Interaction between low molecular weight carboxylic acids and muscovite: Molecular dynamic simulation and experiment study. Colloids Surf., A 2018, 559, $8-17$.

(23) Kang, S.; Xing, B. Adsorption of DAs by clay minerals as examined by in situ ATR-FTIR and ex situ DRIFT. Langmuir 2007, 23, 7024-7031.

(24) Specht, C. H.; Frimmel, F. H. An in situ ATR-FTIR study on the adsorption of DAs onto kaolinite in aqueous suspensions. Phys. Chem. Chem. Phys. 2001, 3, 5444-5449.

(25) Liu, X.; Lu, X.; Wang, R.; Zhou, H.; Xu, S. Surface complexes of acetate on edge surfaces of 2: 1 type phyllosilicate: Insights from density functional theory calculation. Geochim. Cosmochim. Acta 2008, 72, 5896-5907.

(26) Ramos, M. E.; Garcia-Palma, S.; Rozalen, M.; Johnston, C. T.; Huertas, F. J. Kinetics of montmorillonite dissolution: An experimental study of the effect of oxalate. Chem. Geol. 2014, 363, 283-292.

(27) Newcomb, C. J.; Qafoku, N. P.; Grate, J. W.; Bailey, V. L.; De Yoreo, J. J. Developing a molecular picture of soil organic mattermineral interactions by quantifying organo-mineral binding. Nat. Commun. 2017, 8, 1-8.

(28) Kubicki, J.; Schroeter, L.; Itoh, M.; Nguyen, B.; Apitz, S. Attenuated total reflectance Fourier-transform infrared spectroscopy of carboxylic acids adsorbed onto mineral surfaces. Geochim. Cosmochim. Acta 1999, 63, 2709-2725.

(29) Kubicki, J. D.; Itoh, M. J.; Schroeter, L. M.; Apitz, S. E. Bonding mechanisms of salicylic acid adsorbed onto illite clay: an ATR- FTIR and molecular orbital study. Environ. Sci. Technol. 1997, 31, 11511156.

(30) Rashid, M.; Buckley, D.; Robertson, K. Interactions of a marine humic acid with clay minerals and a natural sediment. Geoderma 1972, 8, 11-27.

(31) Lackovic, K.; Johnson, B. B.; Angove, M. J.; Wells, J. D. Modeling the adsorption of citric acid onto Muloorina illite and related clay minerals. J. Colloid Interf. Sci. 2003, 267, 49-59.

(32) Kitadai, N.; Yokoyama, T.; Nakashima, S. In situ ATR-IR investigation of L-lysine adsorption on montmorillonite. J. Colloid Interf. Sci. 2009, 338, 395-401.

(33) Martinez, R. E.; Sharma, P.; Kappler, A. Surface binding site analysis of $\mathrm{Ca} 2+-$ homoionized clay-humic acid complexes. J. Colloid Interf. Sci. 2010, 352, 526-534.

(34) Yeasmin, S.; Singh, B.; Kookana, R. S.; Farrell, M.; Sparks, D. L.; Johnston, C. T. Influence of mineral characteristics on the retention of low molecular weight organic compounds: A batch sorption-desorption and ATR-FTIR study. J. Colloid Interf. Sci. 2014, $432,246-257$.

(35) Tunega, D.; Benco, L.; Haberhauer, G.; Gerzabek, M. H.; Lischka, H. Ab initio molecular dynamics study of adsorption sites on the (001) surfaces of 1: 1 dioctahedral clay minerals. J. Phys. Chem. B 2002, 106, 11515-11525.

(36) Tunega, D.; Aquino, A. J.; Haberhauer, G.; Gerzabek, M. H.; Lischka, H., Hydrogen bonds and solvent effects in soil processes: a theoretical view. In Solvation effects on molecules and biomolecules, Springer: 2008; 321-347.

(37) Aquino, A. J.; Tunega, D.; Haberhauer, G.; Gerzabek, M. H.; Lischka, $\mathrm{H}$. Adsorption of organic substances on broken clay surfaces: a quantum chemical study. J. Comput. Chem. 2003, 24, 1853-1863.

(38) Bergaya, F.; Lagaly, G., Handbook of clay science. Newnes: 2013; 5.

(39) Tunega, D.; Haberhauer, G.; Gerzabek, M. H.; Lischka, H. Theoretical study of adsorption sites on the (001) surfaces of 1: 1 clay minerals. Langmuir 2002, 18, 139-147. 
(40) Majzik, A.; Tombácz, E. Interaction between humic acid and montmorillonite in the presence of calcium ions I. Interfacial and aqueous phase equilibria: Adsorption and complexation. Org. Geochem. 2007, 38, 1319-1329.

(41) Feng, X.; Simpson, A. J.; Simpson, M. J. Chemical and mineralogical controls on humic acid sorption to clay mineral surfaces. Org. Geochem. 2005, 36, 1553-1566.

(42) Kloster, N.; Avena, M. Interaction of humic acids with soil minerals: adsorption and surface aggregation induced by $\mathrm{Ca} 2+$. Environ. Chem. 2015, 12, 731-738.

(43) Liu, A.; Gonzalez, R. D. Adsorption/desorption in a system consisting of humic acid, heavy metals, and clay minerals. J. Colloid Interf. Sci.. 1999, 218, 225-232.

(44) Awad, A. M.; Shaikh, S. M.; Jalab, R.; Gulied, M. H.; Nasser, M. S.; Benamor, A.; Adham, S. Adsorption of organic pollutants by natural and modified clays: a comprehensive review. Sep. Purif. Technol. 2019, 228, 115719.

(45) Gibbs, R. J. Effect of natural organic coatings on the coagulation of particles. Environ. Sci. Technol. 1983, 17, 237-240.

(46) Tombácz, E.; Filipcsei, G.; Szekeres, M.; Gingl, Z. Particle aggregation in complex aquatic systems. Colloids Surf., A 1999, 151, 233-244.

(47) Kretzschmar, R.; Holthoff, H.; Sticher, H. Influence of pH and humic acid on coagulation kinetics of kaolinite: a dynamic light scattering study. J. Colloid Interf. Sci. 1998, 202, 95-103.

(48) Borgnino, L. Experimental determination of the colloidal stability of Fe (III)-montmorillonite: Effects of organic matter, ionic strength and $\mathrm{pH}$ conditions. Colloids Surf., A 2013, 423, 178-187.

(49) Zhang, Y.; Chen, Y.; Westerhoff, P.; Crittenden, J. Impact of natural organic matter and divalent cations on the stability of aqueous nanoparticles. Water Res. 2009, 43, 4249-4257.

(50) Ward, D. B.; Brady, P. V. Effect of $\mathrm{Al}$ and organic acids on the surface chemistry of kaolinite. Clays Clay Miner. 1998, 46, 453-465.

(51) Furukawa, Y.; Watkins, J. L.; Kim, J.; Curry, K. J.; Bennett, R. $\mathrm{H}$. Aggregation of montmorillonite and organic matter in aqueous media containing artificial seawater. Geochem. Trans. 2009, 10, 2.

(52) Jiang, C.-L.; Séquaris, J.-M.; Vereecken, H.; Klumpp, E. Effects of inorganic and organic anions on the stability of illite and quartz soil colloids in Na-, Ca-and mixed Na-Ca systems. Colloids Surf., A 2012, 415, 134-141.

(53) Israelachvili, J.; Min, Y.; Akbulut, M.; Alig, A.; Carver, G.; Greene, W.; Kristiansen, K.; Meyer, E.; Pesika, N.; Rosenberg, K.; Zeng, H. Recent advances in the surface forces apparatus (SFA) technique. Rep. Prog. Phys. 2010, 73, 036601.

(54) Israelachvili, J. N.; Alcantar, N. A.; Maeda, N.; Mates, T. E.; Ruths, M. Preparing contamination-free mica substrates for surface characterization, force measurements, and imaging. Langmuir 2004, $20,3616-3622$.

(55) Israelachvili, J. Thin film studies using multiple-beam interferometry. J. Colloid Interf. Sci. 1973, 44, 259-272.

(56) Schwenzfeier, K. A.; Erbe, A.; Bilotto, P.; Lengauer, M.; Merola, C.; Cheng, H.-W.; Mears, L. L.; Valtiner, M. Optimizing multiple beam interferometry in the surface forces apparatus: Novel optics, reflection mode modeling, metal layer thicknesses, birefringence, and rotation of anisotropic layers. Rev. Sci. Instrum. 2019, 90, No. 043908.

(57) Reithmeier, M.; Erbe, A. Dielectric interlayers for increasing the transparency of metal films for mid-infrared attenuated total reflection spectroscopy. Phys. Chem. Chem. Phys. 2010, 12, 14798-14803.

(58) Horn, R. G.; Smith, D. T. Analytic solution for the three-layer multiple beam interferometer. Appl. Opt. 1991, 30, 59-65.

(59) Dziadkowiec, J.; Javadi, S.; Bratvold, J. E.; Nilsen, O.; Rфyne, A. Surface Forces Apparatus measurements of interactions between rough and reactive calcite surfaces. Langmuir 2018, 34, 7248-7263.

(60) McGuiggan, P. M.; Israelachvili, J. N. Adhesion and short-range forces between surfaces. Part II: Effects of surface lattice mismatch. J. Mater. Res. 1990, 5, 2232-2243.

(61) Momma, K.; Izumi, F. VESTA 3 for three-dimensional visualization of crystal, volumetric and morphology data. J. Appl. Crystallogr. 2011, 44, 1272-1276.
(62) Donaldson, S. H., Jr.; Röyne, A.; Kristiansen, K.; Rapp, M. V.; Das, S.; Gebbie, M. A.; Lee, D. W.; Stock, P.; Valtiner, M.; Israelachvili, J. Developing a general interaction potential for hydrophobic and hydrophilic interactions. Langmuir 2015, 31, 2051-2064.

(63) Hu, Q.; Weber, C.; Cheng, H. W.; Renner, F. U.; Valtiner, M. Anion layering and steric hydration repulsion on positively charged surfaces in aqueous electrolytes. ChemPhysChem 2017, 18, 30563065.

(64) Kristiansen, K.; Valtiner, M.; Greene, G. W.; Boles, J. R.; Israelachvili, J. N. Pressure solution-The importance of the electrochemical surface potentials. Geochim. Cosmochim. Acta 2011, 75, 6882-6892.

(65) Pashley, R. M. Hydration forces between mica surfaces in aqueous-electrolyte solutions. J. Colloid Interf. Sci. 1981, 80, 153-162.

(66) Baimpos, T.; Shrestha, B. R.; Raman, S.; Valtiner, M. Effect of interfacial ion structuring on range and magnitude of electric double layer, hydration, and adhesive interactions between mica surfaces in 0.05-3 M Li+ and Cs+ electrolyte solutions. Langmuir 2014, 30, $4322-4332$.

(67) Nosrati, A.; Addai-Mensah, J.; Skinner, W. pH-mediated interfacial chemistry and particle interactions in aqueous muscovite dispersions. Chem. Eng. J. 2009, 152, 406-414.

(68) Lee, S. S.; Fenter, P.; Nagy, K. L.; Sturchio, N. C. Monovalent ion adsorption at the muscovite (001)-solution interface: Relationships among ion coverage and speciation, interfacial water structure, and substrate relaxation. Langmuir 2012, 28, 8637-8650.

(69) Zachariah, Z.; Espinosa-Marzal, R. M.; Heuberger, M. P. Ion specific hydration in nano-confined electrical double layers. J. Colloid Interf. Sci. 2017, 506, 263-270.

(70) Israelachvili, J., Intermolecular and surface forces. 3rd ed.; Academic Press: 2011.

(71) Daniele, P. G.; Foti, C.; Gianguzza, A.; Prenesti, E.; Sammartano, S. Weak alkali and alkaline earth metal complexes of low molecular weight ligands in aqueous solution. Coord. Chem. Rev. 2008, 252, 1093-1107.

(72) Kobayashi, K.; Liang, Y.; Murata, S.; Matsuoka, T.; Takahashi, S.; Amano, K.-I.; Nishi, N.; Sakka, T. Stability evaluation of cation bridging on muscovite surface for improved description of ion-specific wettability alteration. J. Phys. Chem. C 2017, 121, 9273-9281.

(73) Pashley, R. M. DLVO and Hydration Forces between Mica Surfaces in $\mathrm{Li}^{+}, \mathrm{Na}^{+}, \mathrm{K}^{+}$, and $\mathrm{Cs}^{+}$Electrolyte-Solutions - a Correlation of Double-Layer and Hydration Forces with Surface Cation-Exchange Properties. J. Colloid Interf. Sci. 1981, 83, 531-546.

(74) Parsons, D. F.; Ninham, B. W. Charge reversal of surfaces in divalent electrolytes: The role of ionic dispersion interactions. Langmuir 2010, 26, 6430-6436.

(75) Danov, K. D.; Basheva, E. S.; Kralchevsky, P. A. Effect of ionic correlations on the surface forces in thin liquid films: influence of multivalent coions and extended theory. Materials 2016, 9, 145.

(76) Kjellander, R.; Marcelja, S.; Pashley, R.; Quirk, J. Double-layer ion correlation forces restrict calcium-clay swelling. J. Phys. Chem. 1988, 92, 6489-6492.

(77) Marcelja, S.; Senden, T.; Shubin, V.; Kékicheff, P. Charge reversal seen in electrical double layer interaction of surfaces immersed in 2: 1 calcium electrolyte. J. chem. phys. 1993, 99, 6098-6113.

(78) Daniele, P. G.; De Robertis, A.; De Stefano, C.; Sammartano, S.; Rigano, C. On the possibility of determining the thermodynamic parameters for the formation of weak complexes using a simple model for the dependence on ionic strength of activity coefficients: $\mathrm{Na}+, \mathrm{K}+$, and $\mathrm{Ca} 2+$ complexes of low molecular weight ligands in aqueous solution. J. Chem. Soc., Dalton Trans. 1985, 2353-2361.

(79) Peacock, J.; James, J. Ion association in aqueous solutions of metal dicarboxylates. J. Chem. Soc. (Resumed) 1951, 2233-2239.

(80) Topp, N. E.; Davies, C. W. The extent of dissociation of salts in water. Part IX. Calcium and barium salts of DAs. J. Chem. Soc. (Resumed) 1940, 87-93. 
(81) Parkhurst, D. L.; Appelo, C. Description of input and examples for PHREEQC version 3: a computer program for speciation, batchreaction, one-dimensional transport, and inverse geochemical calculations; US Geological Survey: 2013, 2328-7055.

(82) Tadmor, R.; Chen, N.; Israelachvili, J. Normal and shear forces between mica and model membrane surfaces with adsorbed hyaluronan. Macromolecules 2003, 36, 9519-9526.

(83) Yokoyama, A.; Srinivasan, K. R.; Fogler, H. S. Stabilization mechanism by acidic polysaccharides. Effects of electrostatic interactions on stability and peptization. Langmuir 1989, 5, 534-538.

(84) Berg, J. M.; Claesson, P. M.; Neuman, R. D. Interactions between mica surfaces in sodium polyacrylate solutions containing calcium ions. J. Colloid Interf. Sci. 1993, 161, 182-189.

(85) Wu, B.; Chun, B.-W.; Gu, L.; Kuhl, T. L. Effect of $\mathrm{Ca}^{2+}$ ion concentration on adsorption of poly (carboxylate ether)-based (PCE) superplasticizer on mica. J. Colloid Interf. Sci. 2018, 527, 195-201.

(86) Namjesnik-Dejanovic, K.; Maurice, P. A. Conformations and aggregate structures of sorbed natural organic matter on muscovite and hematite. Geochim. Cosmochim. Acta 2001, 65, 1047-1057. 